\title{
Viscoelastic Mechanical Model of Asphalt Concrete Considering the Influence of Characteristic Parameter of Fiber Content
}

\author{
Chunshui Huang ${ }^{1 *}$, Danying $\mathrm{Gao}^{2}$, Peibo $\mathrm{You}^{3}$ \\ ${ }^{1}$ College of Civil Engineering, Xuchang University, Xuchang 461000, China \\ ${ }^{2}$ Zhengzhou University, Zhengzhou 450000, China \\ ${ }^{3}$ Henan University of Urban Construction, Pingdingshan 467000, China
}

Corresponding Author Email: chunshuihuang@163.com

https://doi.org/10.18280/rcma.310503

Received: 5 July 2021

Accepted: 12 September 2021

\section{Keywords:}

fiber-reinforced asphalt concrete, viscoelastic performance, bending creep test, characteristic parameter of fiber content ( $F C C P$ )

\begin{abstract}
This paper carries out bending creep tests on polyester fiber-reinforced asphalt concrete beams, and investigates how the volume ratio and aspect ratio of the fibers influence the parameters of viscoelastic mechanical model and the viscoelastic performance of the asphalt concrete. The results show that: with the growing volume ratio and aspect ratio of the fibers, the midspan deflection and bottom flexural-tensile strain of asphalt concrete beams first dropped and then rose over time; the characteristic parameter of fiber content (FCCP) could reflect the overall effects of the volume ratio and aspect ratio of the fibers. On this basis, a viscoelastic mechanical model was established for the asphalt concrete in the light of the influence of FCCP. The test and theoretical results show that, in our tests, the optimal volume ratio of fibers, optimal aspect ratio of fibers, and optimal FCCP are $0.348,324$, and 1.128 for polyester fiber-reinforced asphalt concrete.
\end{abstract}

\section{INTRODUCTION}

Asphalt concrete is a typical viscoelastic composite. The influence of temperature and load stress on the viscoelastic properties of asphalt concrete is mainly investigated with different viscoelastic mechanical models composed of basic viscoelastic components (e.g., springs and dampers), based on uniaxial compressive creep, triaxial compressive creep, and beam bending creep tests [1-10].

Since the addition of fibers can significantly improve the road performance of asphalt concrete, more and more attention has been paid to the viscoelastic properties of fiber-reinforced asphalt concrete. Through dynamic and static triaxial tests, Benedito et al. [11] studied the influence of fiber dosage and length on cold-mix asphalt concrete. Guo et al. [12] and Guo et al. [13] conducted compressive creep tests on polyester fiber-reinforced asphalt concrete, and adopted Burgers model and modified Burgers model to examine the influence of fibers of the same length over the viscoelastic performance of asphalt concrete at different dosages. On this basis, Guo established a viscoelastic mechanical model of asphalt concrete considering the influence of fiber dosage. Feng [14] analyzed the effects of fiber length on the performance of asphalt concrete through a pull-out test.

However, many research problems are yet to be solved: How does the aspect ratio of fibers impact the parameters of viscoelastic mechanical model and the viscoelastic performance of asphalt concrete? How do the volume ratio (or dosage) and aspect ratio of fibers affect the viscoelastic mechanical model and the viscoelastic performance of asphalt concrete after unloading? What is the composite influence of the volume ratio and aspect ratio of fibers over the viscoelastic performance of asphalt concrete?

To answer these questions, this paper takes the AC-13F asphalt mixture as the matrix, adopts the volume ratio $V_{f}$ and aspect ratio $R_{a}$ as parameters, and tests the bending creep of polyester fiber-reinforced asphalt concrete beams, based on the optimal asphalt dosage determined by Marshall test. Next, Burgers model and modified Burgers model were employed to systematically analyze the influence of $V_{f}$ and $R_{a}$ over the parameters of viscoelastic mechanical model and the viscoelastic performance of the asphalt concrete during the loading and unloading phases. After that, the composite influence of the two parameters was characterized by the characteristic parameter of fiber content (FCCP) $\lambda_{f}$, and a viscoelastic mechanical model was established for the asphalt concrete considering the influence of $\lambda_{f}$.

\section{METHODOLOGY}

Our tests use petroleum asphalt 70 and polyester fibers with a mean diameter of $18.5 \mu \mathrm{m}$. To study the influence of the volume ratio $V_{f}$ and aspect ratio $R_{a}$ of the fibers, the fiber length was set to $3 \mathrm{~mm}, 6 \mathrm{~mm}$, and $9 \mathrm{~mm}$, respectively; the aspect ratio was set to $162,324,486$, and 649 , respectively. For the polyester fibers of the length $3 \mathrm{~mm}, 9 \mathrm{~mm}$, and $12 \mathrm{~mm}$, the volume ratio was set to $0.351,0.34$, and 0.346 in turn. For those of the length $6 \mathrm{~mm}$, the volume ratio was set to 0.174 , $0.348,0.519$, and 0.686 in turn.

The aggregates were screened, cleaned, and dried, and then mixed with limestone powder back to AC-13 asphalt concrete with medium grading. Through standard Marshall test [15], the optimal asphalt content (OAC) was determined for the 
matrix of asphalt mix, and for the asphalt mix with each volume ratio and aspect ratio of the fibers.

The designed polyester fiber-reinforced asphalt mix was compressed into specimens of $300 \mathrm{~mm} \times 300 \mathrm{~mm} \times 50 \mathrm{~mm}$, and then cut into small beams of $250 \mathrm{~mm} \times 30 \mathrm{~mm} \times 35 \mathrm{~mm}$. Then, creep tests were carried out at $15^{\circ} \mathrm{C}$ on a multi-function material testing machine. The specimens were loaded with weights. The test environment is illustrated in Figure 1. The creep load is $10 \%$ of the bending failure load of the beam under the same conditions.

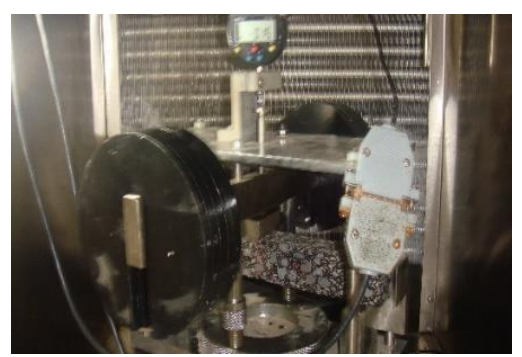

Figure 1. Creep test environment

The creep tests were performed on eight groups of small beams. Each group contains three small beams. During the tests, the midspan deflection $d(t)$ of the small beam being tested was collected by a dial gauge, which is connected to the data acquisition system, and the time-deflection curve was plotted. When the small beam entered accelerated creep phase, the load was removed, and the midspan deflection was collected $30 \mathrm{~min}$ after the unloading. Based on the midspan deflection, the bottom flexural-tensile strain can be calculated by:

$$
\varepsilon(t)=\frac{6 h d(t)}{L^{2}}
$$

where, $h$ is the height of the specimen $(\mathrm{m})$; $\mathrm{L}$ is the span of the specimen $(\mathrm{m})$.

\section{VISCOELASTIC DEFORMATION FEATURES}

Figures 2 and 3 show the time variation of midspan deflection and bottom flexural-tensile strain of the small asphalt concrete beams of different fiber volume ratios and fiber aspect ratios, respectively. It can be observed that, with the growing volume ratio and aspect ratio of the fibers, the midspan deflection and bottom flexural-tensile strain of asphalt concrete beams first dropped and then rose over time, exhibiting a nonlinear trend. The lowest point of the timecreep deformation curve appeared at the fiber volume ratio of 0.348 and the fiber aspect ratio of 324 .

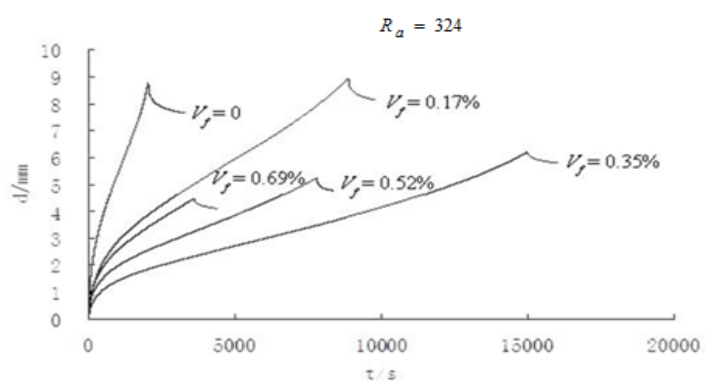

(a) Mid-span deflection

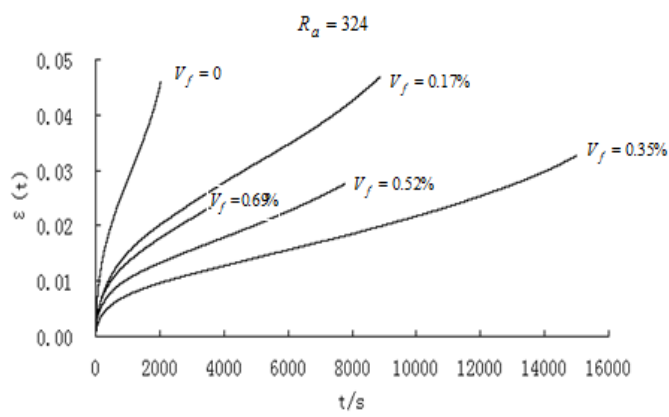

(b) Strain

Figure 2. Relationship between creep deformation and fiber volume ratio

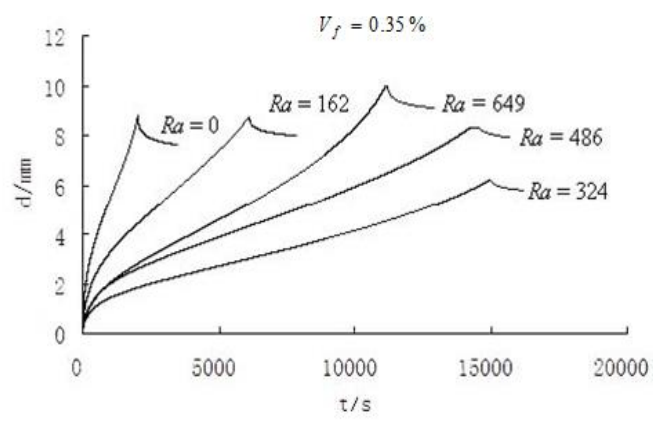

(a) Mid-span deflection

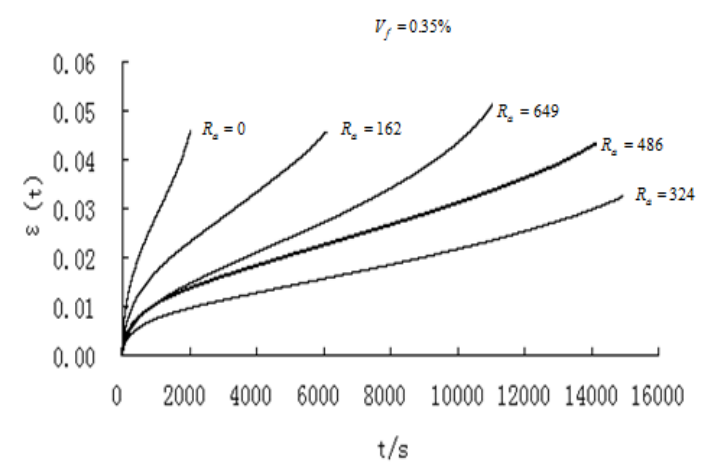

(b) Strain

Figure 3. Relationship between creep deformation and fiber aspect ratio

The reason is that, when the fiber aspect ratio is fixed, the three-dimensional (3D) fiber mesh in the asphalt concrete becomes denser, and the fibers can better constrain the deformation of asphalt concrete. When the fiber volume ratio surpasses 0.348 , the fibers are less dispersive, because the fiber mesh is too dense. The undispersed fibers will cluster into bundles, forming defects in the asphalt concrete [16]. In this case, the fibers will reduce the viscoelastic performance of asphalt concrete, rather than enhance the viscoelasticity. When the fiber volume ratio remains constant, a high fiber aspect ratio means the soft fibers are long, with poor directionality, and easily curled and caked; a small fiber aspect ratio means there are many fibers per unit volume of asphalt concrete, i.e., the fiber mesh is so dense that the fibers are prone to caking, which weakens the reinforcement effect of fibers.

The lower the time-creep deformation curve, the stronger the asphalt concrete against rutting deformation [13]. In our tests, the fiber-reinforced asphalt concrete can resist rutting deformation excellently at the fiber volume ratio of 0.348 and the fiber aspect ratio of 324 . 
It can also be seen from Figures 2 and 3 that, although the fiber-reinforced asphalt concretes with different fiber volume ratios and fiber aspect ratios differed in creep deformation, their time-creep deformation curves all consist of three segments: decelerated creep, constant speed creep, and accelerated creep. The addition of fibers does not change the creep features of the asphalt concrete. Therefore, it is possible to derive a viscoelastic mechanical model for fiber-reinforced asphalt concrete from the viscoelastic mechanical model for ordinary asphalt concrete, by incorporating the fiber influence in model parameters.

\section{VISCOELASTIC MECHANICAL MODEL}

Referring to the Burgers model [7, 13] in Figure 4, the viscoelastic creep equation of the fiber-reinforced asphalt concrete can be expressed as:

Loading phase:

$$
\varepsilon=\sigma_{0}\left(\frac{1}{\mathrm{E}_{1}}+\frac{t}{\eta_{1}}+\frac{1-e^{-t \tau}}{\mathrm{E}_{2}}\right)
$$

Unloading phase:

$$
\varepsilon=\sigma_{0}\left[\frac{t_{0}}{\eta_{1}}+\frac{\left(1-e^{-t_{0} \tau}\right) e^{-\tau\left(t-t_{0}\right)}}{\mathrm{E}_{2}}\right]
$$

where, $E_{l}$ and $\eta_{1}$ are the elastic modulus of elastic element 1 and viscosity of viscous element 4 considering fiber influence, respectively; $E_{2}$ and $\eta_{2}$ are the elastic modulus of elastic element 2 and viscosity of viscous element 3 considering fiber influence, respectively; $\tau=\frac{E_{2}}{\eta_{2}}$.

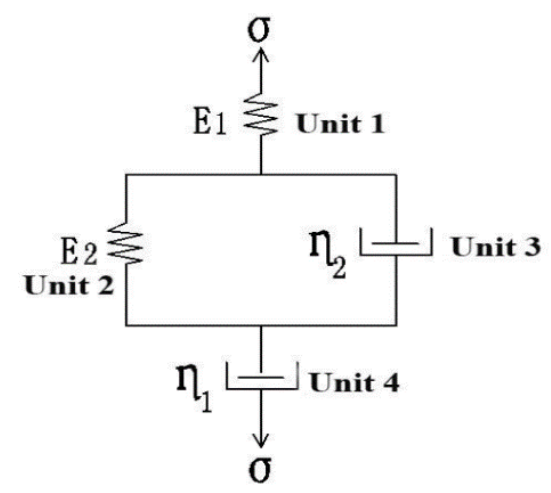

Figure 4. Burgers model

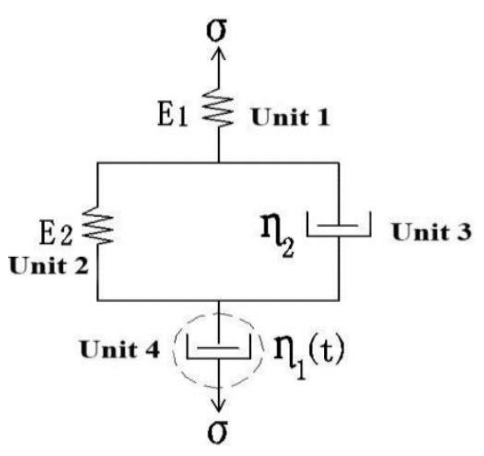

Figure 5. Modified Burgers model
The greater the value of $E_{l}$, the stronger the elastic deformation resistance of the asphalt concrete; the greater the value of $\eta_{1}$, the smaller the permanent deformation induced by the same load in the same period; the greater the value of $\eta_{2} / E_{2}$ the slower the growth of viscous deformation over time, and the shallower the rutting depth on the asphalt concrete pavement; the greater the value of $\eta_{2} / E_{2}$, the slower the development of asphalt concrete deformation, and the stronger the resistance to viscoelastic deformation [1].

Drawing on the modified Burgers model (Figure 5) [8], the viscoelastic creep equation of fiber-reinforced asphalt concrete can be expressed as:

Loading phase:

$$
\varepsilon(t)=\sigma_{0}\left(\frac{1}{\mathrm{E}_{1}}+\frac{1-e^{-B t}}{A B}+\frac{1-e^{-t \tau}}{\mathrm{E}_{2}}\right)
$$

Unloading phase:

$$
\varepsilon(t)=\sigma_{0}\left[\frac{1-e^{-B t_{0}}}{A B}+\frac{\left(1-e^{-t_{0} \tau}\right) e^{-\left(t-t_{0}\right) \tau}}{E_{2}}\right]
$$

where, $\sigma_{0}$ is the test stress; $t$ is the test time; $t_{0}$ is the total loading time.

Based on the creep test results, the parameters of the viscoelastic mechanical model (2)-(5) were initialized through the nonlinear fitting approach of Origin 8.5. By adjusting model parameters, the fitting approach that maximize the matching between theoretical results and the test data was adopted to determine the parameters of the viscoelastic mechanical model. On this basis, the authors analyzed the influence of fiber volume ratio and fiber aspect ratio on model parameters. Then, the FCCP was introduced to reflect the combined effect of fiber volume ratio and fiber aspect ratio, and used to build the constitutive equation of the fiberreinforced asphalt concrete. Finally, the viscoelasticity of the fiber-reinforced asphalt concrete was examined by the creep equation and the constitutive equation.

\subsection{Influence of fiber volume ratio and fiber aspect ratio on viscoelastic model parameters and viscoelastic performance}

Table 1 shows the viscoelastic model parameters of the fiber-reinforced asphalt concrete with different fiber volume ratios and fiber aspect ratios, which are fitted by formula (2). It can be observed that $E_{l}$ first increased and then decreased, with the growing fiber volume ratio. The peak of $E_{l}$ appeared at the fiber volume ratio of 0.348 . In this case, the fiberreinforced asphalt concrete has a strong resistance to the elastic deformation under instantaneous load. When the fiber volume ratio reached 0.686 , the $E_{l}$ of the fiber-reinforced asphalt concrete was smaller than that of the asphalt concrete in the matrix, indicating that the fibers can enhance the elasticity of the fiber-reinforced asphalt concrete only under a proper volume ratio.

With the increase of fiber volume ratio, the $\eta_{I}$ first increased and then declined, suggesting the good thickening effect of a proper dosage of fibers. When the fiber volume ratio was 0.348 , the $\eta_{1}$ more than doubled from that of the asphalt concrete in the matrix. In this case, the fibers exhibit a good thickening effect, and the fiber-reinforced asphalt concrete is 
good at resisting permanent deformation. After the fiber volume ratio reached 0.686 , the fiber-reinforced asphalt concrete had a smaller $\eta_{1}$ than the asphalt concrete in the matrix, that is, an excessive number of fibers would weaken the ability of the asphalt concrete to withstand permanent deformation.

Table 1. Relationship between parameters of formula (2) and fiber volume ratio and fiber aspect ratio

\begin{tabular}{|c|c|c|c|c|c|c|c|c|}
\hline \multirow{2}{*}{$V_{f}$} & \multirow{2}{*}{$R_{a}$} & \multicolumn{4}{|c|}{ Model parameters } & \multirow{2}{*}{$R^{2}$} & \multirow{2}{*}{$\begin{array}{c}\text { Relaxation } \\
\text { time/s }\end{array}$} & \multirow{2}{*}{ Delay time/s } \\
\hline & & $E_{1} / \mathrm{MPa}$ & $E_{2} / \mathrm{MPa}$ & $\eta_{1} / \mathrm{MPa} \cdot \mathrm{s}$ & $\eta_{2} / \mathrm{MPa} \cdot \mathrm{s}$ & & & \\
\hline 0 & 0 & 629 & 110 & 305403 & 30110 & 0.99912 & 485 & 274 \\
\hline 0.174 & 324 & 726 & 144 & 530628 & 43517 & 0.99815 & 731 & 302 \\
\hline 0.348 & 324 & 916 & 161 & 683955 & 51518 & 0.99540 & 746 & 320 \\
\hline 0.519 & 324 & 793 & 148 & 501683 & 46680 & 0.99923 & 633 & 315 \\
\hline 0.686 & 324 & 610 & 122 & 268829 & 36772 & 0.99913 & 315 & 301 \\
\hline 0.351 & 162 & 823 & 144 & 541533 & 43359 & 0.99936 & 658 & 301 \\
\hline 0.347 & 486 & 705 & 139 & 364537 & 43405 & 0.99746 & 517 & 312 \\
\hline 0.346 & 649 & 643 & 125 & 319489 & 37890 & 0.99118 & 497 & 303 \\
\hline
\end{tabular}

Table 2. Relationship between parameters of formula (3) and fiber volume ratio and fiber aspect ratio

\begin{tabular}{ccccccc}
\hline \multirow{2}{*}{$V_{f}$} & \multirow{2}{*}{$R_{a}$} & \multicolumn{3}{c}{ Model parameters } & \multirow{2}{*}{$R^{2}$} & \multirow{2}{*}{ Delay time/s } \\
\cline { 3 - 5 } & & $E_{2} / \mathrm{MPa}$ & $\eta_{1} / \mathrm{MPa} \cdot \mathrm{s}$ & $\eta_{2} / \mathrm{MPa} \cdot \mathrm{s}$ & & \\
\hline 0 & 0 & 343 & 251554 & 109199 & 0.98485 & 318 \\
0.174 & 324 & 386 & 346085 & 145944 & 0.97533 & 378 \\
0.348 & 324 & 406 & 399097 & 170332 & 0.99189 & 420 \\
0.519 & 324 & 379 & 317203 & 140118 & 0.98291 & 370 \\
0.686 & 324 & 345 & 184746 & 119707 & 0.98901 & 347 \\
0.351 & 162 & 369 & 310862 & 141021 & 0.98455 & 382 \\
0.347 & 486 & 364 & 292954 & 139592 & 0.99533 & 383 \\
0.346 & 649 & 349 & 266937 & 123008 & 0.98254 & 352 \\
\hline
\end{tabular}

The relaxation time $\eta_{1} / E_{1}$ and delay time $\eta_{2} / E_{2}$ of the fiberreinforced asphalt concrete both increased and then decreased with the growth of fiber volume ratio. Therefore, a proper dosage of fibers could enhance the resistance of the asphalt concrete to rutting deformation. The relaxation time and delay time reached the peak at the fiber volume ratio of 0.348 . In this case, the fibers significantly enhance the resistance of the asphalt concrete to rutting deformation [17].

$E_{1}, \eta_{1}, \eta_{1} / E_{1}$ and $\eta_{2} / E_{2}$ all increased first and then dropped with the growth of fiber aspect ratio, and peaked at the fiber aspect ratio of 324 . In this case, the fiber-reinforced asphalt concrete boasts a strong capability to resist elastic deformation, viscous flow deformation, and rutting deformation.

Table 3 shows the viscoelastic model parameters of the fiber-reinforced asphalt concrete with different fiber volume ratios and fiber aspect ratios, which are fitted by formula (3). It can be observed that, $E_{2}$ and $\eta_{2}$ were much greater than those in the creep loading phase; the delay time $\eta_{2} / E_{2}$ was longer than that in the creep loading phase; $\eta_{I}$ was much smaller than that in that phase.

This is because the asphalt concrete suffers from creep failure in the accelerated creep phase. During the load-induced bending creep deformation, the internal aggregates of each small asphalt concrete beam slip, causing material damage and performance attenuation. The actual permanent deformation, which is characterized by the parameters of the loading phase model, is greater than the theoretical permanent deformation, which is characterized by the parameters of the unloading phase model. Besides, the actual deformation recovery rate, which is characterized by the parameters of the loading phase model, is smaller than the theoretical deformation recovery rate, which is characterized by the parameters of the unloading phase model. Therefore, the actual deformation features of the unloaded asphalt concrete cannot be characterized by the mechanical model parameters obtained in the creep loading phase.
$E_{2}, \eta_{1}$ and $\eta_{2}$ all increased first and then decreased with the growth of fiber volume ratio and fiber aspect ratio. The peak values were observed at the fiber volume ratio of 0.348 and the fiber aspect ratio of 324 . The variation law was the same as that in the creep loading phase.

It can also be seen from Table 2 that the correlation between test data and formula (3) in the creep unloading phase was weaker than that in the creep loading phase. Overall, formulas (2) and (3) can characterize the viscoelastic deformation features of asphalt concrete excellently during the loading phase.

Table 3 shows the viscoelastic model parameters of the fiber-reinforced asphalt concrete with different fiber volume ratios and fiber aspect ratios, which are fitted by formula (4). It can be observed that formula (4) is more closely correlated with the test data in the creep loading phase than formula (2). The parameters of formula (4), namely, $E_{1}, E_{2}, \eta_{2}, \mathrm{~A}$ and $\mathrm{B}$ all first increased and then decreased with the growth of fiber volume ratio and fiber aspect ratio. The peak values were observed at the fiber volume ratio of 0.348 and the fiber aspect ratio of 324. In this case, the fiber-reinforced asphalt concrete boasts a strong capability to resist elastic deformation, viscous flow deformation, and rutting deformation.

Table 4 shows the viscoelastic model parameters of the fiber-reinforced asphalt concrete with different fiber volume ratios and fiber aspect ratios, which are fitted by formula (5). It can be observed that the parameters of formula (5), namely, $E_{2}, \eta_{2}, \mathrm{~A}$ and $\mathrm{B}$ all first increased and then decreased with the growth of fiber volume ratio and fiber aspect ratio. The peak values were observed at the fiber volume ratio of 0.348 and the fiber aspect ratio of 324 . The change law was the same as that in formula (4). The only difference between formulas (5) and (4) lies in the variation of the value of the same parameter.

Compared with those in the creep loading phase, the model parameters $E_{2}$ and B were relatively large, and $\eta_{2}$ and A were relatively small in the creep unloading phase. This 
phenomenon indicates that the asphalt concrete recovers slower from viscoelastic deformation, and deforms more significantly than the theoretical permanent deformation, after being damaged in creep loading. Although formulas (4) and (5) describe different creep phases from formulas (2) and (3), the changes of their parameters demonstrate the same influence law of creep loading damages on material performance.

It can also be learned from Table 4 that formula (5) is much less correlated with the test data in the creep unloading phase than formula (4), and slightly less correlated with the test data in that phase than formula (3). Hence, formulas (4) and (5) are not as good as formulas (2) and (3) in characterizing the deformation features of unloaded asphalt concrete. To sum up, formulas (4) and (5) work well in characterizing the deformation features of the asphalt concrete and fiberreinforced asphalt concrete in the loading phase, while formulas (2) and (3) work well in characterizing the deformation features of the asphalt concrete and fiberreinforced asphalt concrete in the unloading phase.

Table 3. Relationship between parameters of formula (4) and fiber volume ratio and fiber aspect ratio

\begin{tabular}{|c|c|c|c|c|c|c|c|c|}
\hline \multirow{2}{*}{$V_{f}$} & \multirow{2}{*}{$R_{a}$} & \multicolumn{5}{|c|}{ Model parameters } & \multirow{2}{*}{$R^{2}$} & \multirow{2}{*}{ Delay time/s } \\
\hline & & $E_{1} / \mathrm{MPa}$ & $E_{2} / \mathrm{MPa}$ & $\eta_{2} / \mathrm{MPa} \cdot \mathrm{s}$ & $A / \mathrm{MPa}$ & $B / \mathrm{MPa}$ & & \\
\hline 0 & 0 & 492 & 112 & 339492 & 38117 & 0.000200 & 0.9993 & 3031 \\
\hline 0.174 & 324 & 559 & 131 & 669852 & 72641 & 0.000934 & 0.9993 & 5113 \\
\hline 0.348 & 324 & 593 & 150 & 889472 & 98567 & 0.00136 & 0.99926 & 5930 \\
\hline 0.519 & 324 & 535 & 127 & 665517 & 77429 & 0.000971 & 0.99958 & 5240 \\
\hline 0.686 & 324 & 438 & 107 & 326221 & 45928 & 0.000205 & 0.99925 & 3049 \\
\hline 0.351 & 162 & 541 & 137 & 624197 & 64975 & 0.00074 & 0.99951 & 4556 \\
\hline 0.347 & 486 & 531 & 128 & 565538 & 68834 & 0.00094 & 0.99924 & 4418 \\
\hline 0.346 & 649 & 437 & 115 & 355095 & 47915 & 0.00014 & 0.99905 & 3088 \\
\hline
\end{tabular}

Table 4. Relationship between parameters of formula (5) and fiber volume ratio and fiber aspect ratio

\begin{tabular}{|c|c|c|c|c|c|c|c|}
\hline \multirow{2}{*}{$V_{f}$} & \multirow{2}{*}{$R_{a}$} & \multicolumn{4}{|c|}{ Model parameters } & \multirow{2}{*}{$R^{2}$} & \multirow{2}{*}{ Delay time/s } \\
\hline & & $E_{2} / \mathrm{MPa}$ & $\eta_{2} / \mathrm{MPa} \cdot \mathrm{s}$ & $A / \mathrm{MPa}$ & $B / \mathrm{MPa}$ & & \\
\hline 0 & 0 & 340 & 109197 & 10026 & 0.00200 & 0.98483 & 321 \\
\hline 0.174 & 324 & 408 & 144943 & 17190 & 0.00373 & 0.97530 & 355 \\
\hline 0.348 & 324 & 443 & 170330 & 22814 & 0.00517 & 0.99188 & 384 \\
\hline 0.519 & 324 & 399 & 148935 & 20522 & 0.00369 & 0.98290 & 373 \\
\hline 0.686 & 324 & 349 & 118508 & 15704 & 0.00195 & 0.98640 & 340 \\
\hline 0.351 & 162 & 369 & 140984 & 16013 & 0.00302 & 0.98454 & 382 \\
\hline 0.347 & 486 & 361 & 135420 & 19697 & 0.00312 & 0.99532 & 375 \\
\hline 0.346 & 649 & 347 & 122922 & 15789 & 0.00189 & 0.98253 & 354 \\
\hline
\end{tabular}

\subsection{Viscoelastic model and viscoelasticity analysis}

The above analysis shows that fiber volume ratio $V_{f}$ and fiber aspect ratio $R_{a}$ are important impactors of the viscoelastic performance of the asphalt concrete. This paper chooses the FCCP $\lambda_{f}=V_{f} \times R_{a}$ to represent the overall impact of $V_{f}$ and $R_{a}$ [18]. The model parameters of formulas (2)-(5) all exhibit the same change law with the growth of FCCP: increasing first before declining. By nonlinear fitting of our test data, the relationship between the model parameters of formulas (2) and (3) and the FCCP can be expressed as:

Loading phase:

$$
\begin{gathered}
\mathrm{E}_{1}\left(\lambda_{f}\right)=603.55+454.29 \lambda_{f}-201.49 \lambda_{f}^{2} \\
\mathrm{E}_{2}\left(\lambda_{f}\right)=109.81+82.27 \lambda_{f}-34.66 \lambda_{f}^{2} \\
\eta_{1}\left(\lambda_{f}\right)=298232.9+627942.9 \lambda_{f}-290013 \lambda_{f}^{2} \\
\eta_{2}\left(\lambda_{f}\right)=29864.95+33547.72 \lambda_{f}-13724.8 \lambda_{f}^{2}
\end{gathered}
$$

Unloading phase:

$$
\begin{gathered}
\mathrm{E}_{2}\left(\lambda_{f}\right)=343.43+103.25 \lambda_{f}-46.58 \lambda_{f}^{2} \\
\eta_{1}\left(\lambda_{f}\right)=247449.9+275225.8 \lambda_{f}-136606 \lambda_{f}^{2}
\end{gathered}
$$

$$
\eta_{2}\left(\lambda_{f}\right)=109657.3+89963.02 \lambda_{f}-39147.1 \lambda_{f}^{2}
$$

Substituting formulas (6)-(9) and formulas (10)-(12) into formulas (2) and (3), respectively, the creep equation of the fiber-reinforced asphalt concrete can be established considering the influence of the FCCP:

Loading phase:

$$
\varepsilon\left(t, \lambda_{f}\right)=\sigma_{0}\left[\frac{1}{E_{1}\left(\lambda_{f}\right)}+\frac{t}{\eta_{1}\left(\lambda_{f}\right)}+\frac{1-e^{-t \tau}}{E_{2}\left(\lambda_{f}\right)}\right]
$$

Unloading phase:

$$
\varepsilon\left(t, \lambda_{f}\right)=\sigma_{0}\left[\frac{t_{0}}{\eta_{1}\left(\lambda_{f}\right)}+\frac{\left(1-e^{-t_{0} \tau}\right) e^{-\left(t-t_{0}\right)}}{E_{2}\left(\lambda_{f}\right)}\right]
$$

where, $\tau=E_{2}\left(\lambda_{f}\right) / \eta_{2}\left(\lambda_{f}\right)$.

Finding the derivative of formulas (13) and (14) relative to time $t$, respectively, the differential constitutive equation of the fiber-reinforced asphalt concrete can be established considering the influence of the FCCP:

Loading phase:

$$
d \varepsilon\left(t, \lambda_{f}\right) / d t=\dot{\varepsilon}\left(t, \lambda_{f}\right)=\sigma_{0}\left[\frac{1}{\eta_{1}\left(\lambda_{f}\right)}+\frac{e^{-t \tau}}{\eta_{2}\left(\lambda_{f}\right)}\right]
$$


Unloading phase:

$$
d \varepsilon\left(t, \lambda_{f}\right) / d t=\dot{\varepsilon}\left(t, \lambda_{f}\right)=\sigma_{0}\left[\frac{\left(e^{-t_{0} \tau}-1\right) e^{-\left(t-t_{0}\right) \tau}}{\eta_{2}\left(\lambda_{f}\right)}\right]
$$

Figure 6 shows the relationship between creep strain and the FCCP obtained by formula (13). Under the same loading time and different stress levels, the creep strain always decreased first and then increased with the growth of the FCCP, and reached the minimum at the FCCP of 1.128 . This is very close to the test results. The greater the stress, and the longer the loading, the more significant the creep strain of the fiberreinforced asphalt concrete.

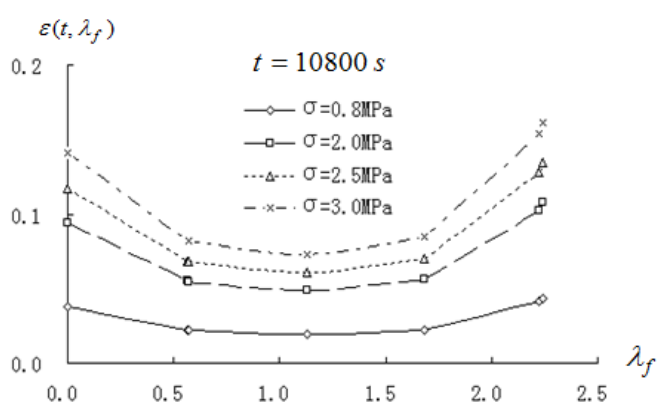

Figure 6. Relationship between creep strain and FCCP

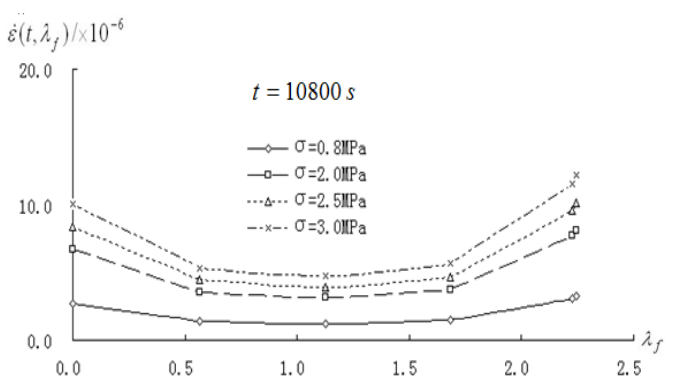

Figure 7. Relationship between creep rate and FCCP

Figure 7 shows the relationship between creep rate and the FCCP obtained by formula (15). It can be observed that, the creep rate first decreased and then increased, with the growth of the FCCP, and minimized at the FCCP of 1.128. This is also very close to the test results. The greater the stress, the faster the creep. With the elapse of the loading time, the creep rate continued to slow down.

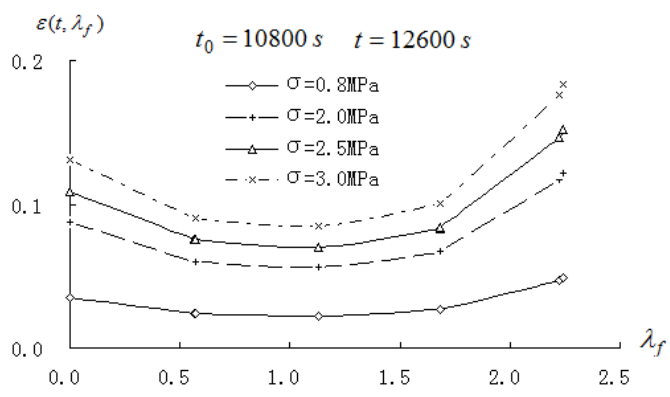

Figure 8. Relationship between creep strain and FCCP after unloading

Figure 8 shows the relationship between creep strain of the fiber-reinforced asphalt concrete after unloading with the FCCP. It can be inferred that the residual creep deformation after unloading increased with the loading stress. The residual creep deformation first increased and then decreased, with the growth of the FCCP. After fixing the time of loading and unloading, the FCCP was 1.128 corresponding to the minimum residual creep deformation of the fiber-reinforced asphalt concrete, under different loading stresses. In this case, the fiber-reinforced asphalt concrete has a strong ability to recover from creep deformation. Formula (14) also reveals that the residual creep deformation increases with the time of creep loading.

Figure 9 shows the relationship between creep rate the fiberreinforced asphalt concrete after unloading with the FCCP. It can be inferred that, due to the inertia of elastic deformation recover after unloading, the greater the loading stress, the faster the recovery from creep deformation. With the growth of the FCCP, the creep recovery rate first increased and then decreased. After fixing the time of loading and unloading, the FCCP was 1.128 corresponding to the maximum creep recovery rate of the fiber-reinforced asphalt concrete, under different loading stresses. In this case, the fiber-reinforced asphalt concrete has a strong ability to recover from creep deformation. Formula (16) also reveals that the longer the loading time, the greater the damages of the fiber-reinforced asphalt concrete induced by creep load, and the smaller the recovery rate from the creep deformation.

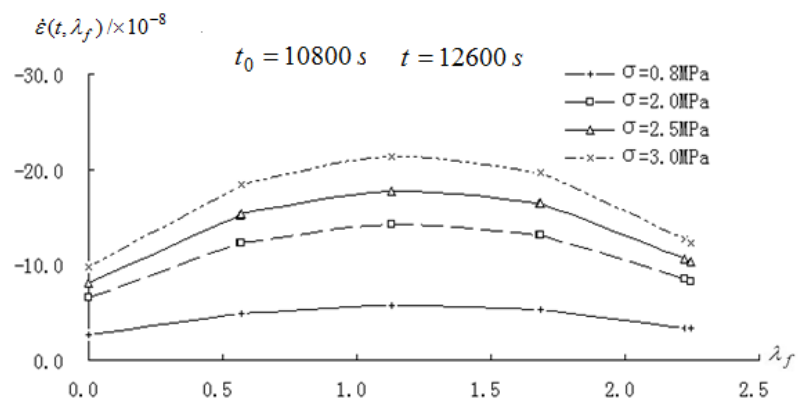

Figure 9. Relationship between creep rate and FCCP after unloading

By nonlinear fitting of our test data, the relationship between the model parameters of formulas (4) and (5) and the FCCP can be expressed as:

Loading phase:

$$
\begin{gathered}
\mathrm{E}_{1}\left(\lambda_{f}\right)=489.33+193.48 \lambda_{f}-97.46 \lambda_{f}^{2} \\
\mathrm{E}_{2}\left(\lambda_{f}\right)=110.91+59.49 \lambda_{f}-27.82 \lambda_{f}^{2} \\
\eta_{2}\left(\lambda_{f}\right)=327619+914046 \lambda_{f}-412653 \lambda_{f}^{2} \\
\mathrm{~A}\left(\lambda_{f}\right)=36674.63+95928.89 \lambda_{f}-41400.4 \lambda_{f}^{2} \\
\mathrm{~B}\left(\lambda_{f}\right)=1.76 \times 10^{-4}+1.975 \times 10^{-3} \lambda_{f}-8.8 \times 10^{-4} \lambda_{f}^{2}
\end{gathered}
$$

Unloading phase:

$$
\mathrm{E}_{2}\left(\lambda_{f}\right)=340.60+164.24 \lambda_{f}-72.98 \lambda_{f}^{2}
$$




$$
\begin{gathered}
\eta_{2}\left(\lambda_{f}\right)=108072.8+96344.6 \lambda_{f}-41409.7 \lambda_{f}^{2} \\
\mathrm{~A}\left(\lambda_{f}\right)=9729.09+18998.79 \lambda_{f}-7340.91 \lambda_{f}^{2} \\
\mathrm{~B}\left(\lambda_{f}\right)=1.916 \times 10^{-3}+ \\
5.062 \times 10^{-3} \lambda_{f}-2.28 \times 10^{-3} \lambda_{f}^{2}
\end{gathered}
$$

Substituting formulas (17)-(21) and formulas (22)-(25) into formulas (4) and (5), respectively, the creep equation of the fiber-reinforced asphalt concrete can be established considering the influence of the FCCP:

Loading phase:

$$
\varepsilon\left(t, \lambda_{f}\right)=\sigma_{0}\left[\frac{1}{\mathrm{E}_{1}\left(\lambda_{f}\right)}+\frac{1-e^{-B\left(\lambda_{f}\right) t}}{A\left(\lambda_{f}\right) B\left(\lambda_{f}\right)}+\frac{1-e^{-t \tau}}{\mathrm{E}_{2}\left(\lambda_{f}\right)}\right]
$$

Unloading phase:

$$
\varepsilon\left(t, \lambda_{f}\right)=\sigma_{0}\left[\frac{1-e^{-\mathrm{B}\left(\lambda_{f}\right) t_{0}}}{A\left(\lambda_{f}\right) B\left(\lambda_{f}\right)}+\frac{\left(1-e^{-t_{0} \tau}\right) e^{-\left(t-t_{0}\right) \tau}}{\mathrm{E}_{2}\left(\lambda_{f}\right)}\right]
$$

where, $\tau=E_{2}\left(\lambda_{f}\right) / \eta_{2}\left(\lambda_{f}\right)$.

Finding the derivative of formulas (26) and (27) relative to time $t$, respectively, the differential constitutive equation of the fiber-reinforced asphalt concrete can be established based on formulas (4) and (5) considering the influence of the FCCP:

Loading phase:

$$
d \varepsilon\left(t, \lambda_{f}\right) / d t=\dot{\varepsilon}\left(t, \lambda_{f}\right)=\sigma_{0}\left[\frac{e^{-B\left(\lambda_{f}\right) t}}{A\left(\lambda_{f}\right)}+\frac{e^{-t \tau}}{\eta_{2}\left(\lambda_{f}\right)}\right]
$$

Unloading phase:

$$
d \varepsilon\left(t, \lambda_{f}\right) / d t=\dot{\varepsilon}\left(t, \lambda_{f}\right)=\sigma_{0}\left[\frac{\left(e^{-t_{0} \tau}-1\right) e^{-\left(t-t_{0}\right) \tau}}{\eta_{2}\left(\lambda_{f}\right)}\right]
$$

The creep equation and differential constitutive equation of the fiber-reinforced asphalt concrete derived from formula (4), and those derived from formula (2) can yield consistent results on the correlations of creep strain and creep rate with the FCCP, stress, and loading time. Similarly, The creep equation and differential constitutive equation derived from formula (5), and those derived from formula (3) can yield consistent results on the correlations of post-unloading creep strain and creep rate with the FCCP, stress, and loading time.

\section{CONCLUSIONS}

(1) With the growing volume ratio and aspect ratio of the fibers, the midspan deflection and bottom flexural-tensile strain of asphalt concrete beams first dropped and then rose over time. The lowest point of the time-creep deformation curve appeared at the fiber volume ratio of 0.348 and the fiber aspect ratio of 324 . In this case, the fiber-reinforced asphalt concrete can resist rutting deformation excellently at the fiber volume ratio of 0.348 and the fiber aspect ratio of 324 .

(2) The creep loading parameters of formulas (2) and (3) and the creep unloading parameters of formulas (4) and (5) all increased first and then decreased with the growth of fiber volume ratio and fiber aspect ratio. At the fiber volume ratio of 0.348 and the fiber aspect ratio of 324 , the fiber-reinforced asphalt concrete is good at resisting elastic deformation, viscous flow deformation, and rutting deformation.

(3) The FCCP can reflect the overall effect of fiber volume ratio and fiber aspect ratio. Formulas (15) and (16) or formulas (28) and (29) are the viscoelastic constitutive equations of the fiber-reinforced asphalt concrete considering the influence of the FCCP. The greater the loading stress and the longer the loading time, the higher the creep strain and creep rate, the faster the recovery from creep deformation after unloading, and the larger the residual creep deformation. Creep strain, creep rate, and residual creep deformation after unloading all increased first and then decreased, with the growth of the FCCP. The optimal FCCP was 1.128 for polyester fibers.

\section{ACKNOWLEDGMENT}

The authors gratefully acknowledge the financial support of the project from the Colleges and Universities Key Scientific Research Projects of Henan Province (Grant No. 20A580006) and Horizontal Research Project of Xuchang University (Grant No. 2019HX005) and The Scientific Research Innovation Team of Xuchang University.

\section{REFERENCES}

[1] Min, Z.H., Wang, X., Huang, W. (2004). Study on performance of epoxy asphalt concrete. Journal of Highway and Transportation Research and Development, 1(1): 1-4. 10.3969/j.issn.1002-0268.2004.01.001

[2] Lundström, R., Isacsson, U. (2004). Linear viscoelastic and fatigue characteristics of styrene-butadiene-styrene modified asphalt mixtures. Journal of Materials in Civil Engineering, 16(6): 629-638. https://doi.org/10.1061/(ASCE)08991561(2004)16:6(629)

[3] Polacco, G., Stastna, J., Biondi, D., Zanzotto, L. (2006). Relation between polymer architecture and nonlinear viscoelastic behavior of modified asphalts. Current Opinion in Colloid \& Interface Science, 11(4): 230-245. https://doi.org/10.1016/j.cocis.2006.09.001

[4] Judycki, J. (1992). Non-linear viscoelastic behaviour of conventional and modified asphaltic concrete under creep. Materials and Structures, 25(2): 95-101. https://doi.org/10.1007/BF02472462

[5] Erkens, S.M.J.G., Liu, X., Scarpas, A. (2002). 3D finite element model for asphalt concrete response simulation. The International Journal Geomechanics, 2(3): 305-330. https://doi.org/10.1061/(ASCE)15323641(2002)2:3(305)

[6] Blab, R., Harvey, J.T. (2002). Modeling measured 3D tire contact stresses in a viscoelastic FE pavement model. The International Journal Geomechanics, 2(3): 271-290. https://doi.org/10.1061/(ASCE)15323641(2002)2:3(271) 
[7] Yang, T.Q. (1990). Viscoelastic mechanics. Wuhan: Centra China University of Technology Press, pp. 8-28.

[8] Xu, S.F. (1992). A rheological model representing the deformation behavior of asphalt mixtures. Mechanics in Engineering, 14(1): 37-40.

[9] Ye, Y. (2009). The experience research of viscoelastoplastic constitute model of asphalt mixture. Wuhan: Solid Mechanics of Huazhong University of Science and Technology.

[10] Zhang, J.P., Xu, L., Wang, B. (2010). Modification of creep model of asphalt mixture and parameters determination. Journal of Wuhan University of Technology(Transportation Science \& Engineering), 34(4): 699-702.

[11] Benedito, S.B., Wander, R.S., Dario, C.L. (2003). Engineering properties of fiber reinforced cold asphalt mixes. Jour-nal of Environmental Engineering, 129(10): 952-955. https://doi.org/10.1061/(ASCE)07339372(2003)129:10(952)

[12] Guo, N.S., Zhao, Y.H., Sun, L.L. (2004). Study on creep performance of fiber reinforced asphalt concrete. Journal of China \& Foreign Highway, 1(1): 124-127. https://doi.org/10.3969/j.issn.1671-2579.2007.02.032

[13] Guo, N.S., Zhao, Y.H., Sun, L.L. (2007). Viscoelastic performance analysis of fiber reinforced asphalt concrete. Journal of Traffic and Transportation Engineering, 10(5):
$37-40$

1637.2007.05.009

https://doi.org/10.3321/j.issn:1671-

[14] Feng, J.L. (2007). Studie of performance and mechanism of fiber reinforced asphalt mixtures. Nanjing: Department of Road and Railway Engineering of Dongnan University. https://doi.org/10.7666/d.y1040654

[15] JTJ 052-2000. (2000). Standard test methods of bitumen and bituminous mixtures for highway engineering. Beijing: China Communications Press.

[16] Chen, H.X., Zhang, Z.Q., Hu, C.S. (2004). Lowtemperature anti-cracking performance of fiberreinforced asphalt mixture. Huanan Ligong Daxue Xuebai(Ziran Kexue Ban)/ Journal of South China University of Technology(Natural Science Edition)(China), 32(4): 82-86. https://doi.org/https://doi.org/10.1007/BF02911033

[17] Szydlo, A., Mackiewicz, P. (2005). Asphalt mixes deformation sensitivity to change in rheological parameters. Journal of Materials in Civil Engineering, 17(1): $\quad 1-9$. https://doi.org/10.1061/(ASCE)08991561(2005)17:1(1)

[18] Gao, D.Y., Liu, J.X. (1994). Basic theory for steel fiber reinforced concrete. Beijing: Science and Technology Literature Press, pp. 9-14. 